\title{
Correction to: Gas turbine computational flow and structure analysis with isogeometric discretization and a complex-geometry mesh generation method
}

\author{
Yuri Bazilevs $^{1} \cdot K$ Kenji Takizawa ${ }^{2} \cdot$ Michael C. H. Wu ${ }^{1} \cdot$ Takashi Kuraishi $^{3} \cdot$ Reha Avsar $^{3} \cdot$ Zhaojing Xu $^{2}$. \\ Tayfun E. Tezduyar ${ }^{3,4}$
}

Published online: 21 December 2020

(c) The Author(s) 2020

\section{Correction to: \\ Computational Mechanics https://doi.org/10.1007/s00466-020-01919-w}

An earlier version of this article included a number of typesetting mistakes. These were corrected on October 16, 2020. The publisher apologizes for the errors made during production. The symbol " $\boldsymbol{\Lambda}_{\mathrm{n}}$ " was incorrectly published as " $\Gamma_{\mathrm{n}}$ " in the equations (46) and (47). The correct equations are provided in this correction.

$$
\begin{aligned}
\left\{\hat{\mathbf{A}}_{\mathrm{n}}\right\}_{-} & =\mathbf{M T}\left\{\boldsymbol{\Lambda}_{\mathrm{n}}\right\}_{-} \mathbf{T}^{-1} \mathbf{M}^{-1}, \\
\boldsymbol{\Lambda}_{\mathrm{n}}= & {\left[\begin{array}{llllc}
u_{n} & 0 & 0 & 0 & 0 \\
0 & u_{n} & 0 & 0 & 0 \\
0 & 0 & u_{n} & 0 & 0 \\
0 & 0 & 0 & u_{n}+c & 0 \\
0 & 0 & 0 & 0 & u_{n}-c
\end{array}\right] }
\end{aligned}
$$

The original article can be found online at https://doi.org/10.1007/s00 466-020-01919-w.

Kenji Takizawa

kenji.takizawa@tafsm.org

Yuri Bazilevs

yuri_bazilevs@brown.edu

Tayfun E. Tezduyar

tezduyar@tafsm.org

1 School of Engineering, Brown University, 184 Hope St., Providence, RI 02912, USA

2 Department of Modern Mechanical Engineering, Waseda University, 3-4-1 Ookubo, Shinjuku-ku, Tokyo 169-8555, Japan

3 Mechanical Engineering, Rice University, MS 321, 6100 Main Street, Houston, TX 77005, USA

4 Faculty of Science and Engineering, Waseda University, 3-4-1 Ookubo, Shinjuku-ku, Tokyo 169-8555, Japan
Table 5 Mesh data for the quadratic NURBS and linear tetrahedral meshes

\begin{tabular}{lrr}
\hline & NURBS & Tetrahedral \\
\hline Number of elements & 393,274 & $10,950,909$ \\
Number of points/nodes & 716,706 & $2,037,853$ \\
Blade element height $(\mathrm{mm})$ & 0.3 & 0.6 \\
\hline
\end{tabular}

Also under the section " 4.3 Weak-boundary-condition operator", the sentence "It $\Gamma_{n}$ is computed, based on the eigenvalue decomposition $\boldsymbol{\Gamma}_{\mathrm{n}} \mathbf{T}^{-1}$ associated with hyperbolic equation systems (see, e.g., [196]), using the expression" above the equation (46) should read as "It is computed, based on the eigenvalue decomposition $\mathbf{T} \boldsymbol{\Lambda}_{\mathrm{n}} \mathbf{T}^{-1}$ associated with hyperbolic equation systems (see, e.g., [196]), using the expression" and the sentence "is the matrix of transformation from the vector $\left[\rho \mathbf{u}^{\mathrm{T}} p\right]^{\mathrm{T}}$ to $\mathbf{U}$, and $\left\{\Gamma_{\mathrm{n}}\right\}_{-}$is the negative part of $\Gamma_{\mathrm{n}}$, which is easily computed." below the equation (49) should read as "is the matrix of transformation from the vector $\left[\rho \mathbf{u}^{\mathrm{T}} p\right]^{\mathrm{T}}$ to $\mathbf{U}$, and $\left\{\boldsymbol{\Lambda}_{\mathrm{n}}\right\}_{-}$is the negative part of $\boldsymbol{\Lambda}_{\mathrm{n}}$, which is easily computed".

Further, the values in the Table 5 was published incorrectly. The correct table is provided in this correction (Table 5).

The original article has been corrected.

Open Access This article is licensed under a Creative Commons Attribution 4.0 International License, which permits use, sharing, adaptation, distribution and reproduction in any medium or format, as long as you give appropriate credit to the original author(s) and the source, provide a link to the Creative Commons licence, and indicate if changes were made. The images or other third party material in this article are included in the article's Creative Commons licence, unless indicated otherwise in a credit line to the material. If material is not included in the article's Creative Commons licence and your intended use is not permitted by statutory regulation or exceeds the permitted use, you will need to obtain permission directly from the copyright holder. To view a copy of this licence, visit http://creativecomm ons.org/licenses/by/4.0/. 
Publisher's Note Springer Nature remains neutral with regard to jurisdictional claims in published maps and institutional affiliations. 